Review

\title{
Laparoscopic cryoablation vs. percutaneous cryoablation for treatment of small renal masses: a systematic review and meta- analysis
}

\author{
Kehua Jiang ${ }^{1,2, *}$, Kun Tang ${ }^{1, *}$, Xiaolin Guo ${ }^{1}$, Haoran Liu ${ }^{1}$, Hongbo Chen ${ }^{2}$, Zhiqiang \\ Chen $^{1}$, Hua $X u^{1}$ and Zhangqun $\mathrm{Ye}^{1}$ \\ ${ }^{1}$ Department of Urology, Institute of Urology, Tongji Hospital, Tongji Medical College, Huazhong University of Science and \\ Technology, Wuhan, China \\ 2 Department of Urology, The Central Hospital of Enshi Tujia and Miao Autonomous Prefecture, Enshi, China \\ * These authors have contributed equally to this work
}

Correspondence to: Hua XU, email: xuhuawhu@163.com

Keywords: Laparoscopic cryoablation; percutaneous cryoablation; small renal masses; meta-analysis

Received: July 22, $2016 \quad$ Accepted: January 23, $2017 \quad$ Published: February 10, 2017

Copyright: Jiang et al. This is an open-access article distributed under the terms of the Creative Commons Attribution License (CC-BY), which permits unrestricted use, distribution, and reproduction in any medium, provided the original author and source are credited.

\section{ABSTRACT}

CONTEXT: Laparoscopic cryoablation (LCA) and percutaneous cryoablation(PCA) have been used on patients with small renal masses(SRMs) for many years. However, clinical studies assessing their feasibility and safety have reported contradictory outcomes. This systematic evaluation was performed to obtain comprehensive evidence with regard to the feasibility and safety of PCA compared with LCA.

METHODS: A systematic search of Embase, Pubmed, Medline, the Cochrane Library were performed to identify studies that compared LCA with PCA were published up to Mar 2016. Outcomes of interest included perioperative, pathologic variables, and complications.

RESULTS: Thirteen studies estimating LCA versus PCA were included for metaanalysis. Patients undergoing PCA were significantly older(WMD $=-0.16$ years; $P$ $=0.01$ ) and patients with posterior tumors were significantly prefer undergoing PCA than $\operatorname{LCA}(\mathrm{OR}=0.23 ; P=0.0007)$, whereas patients with anterior tumors were significantly prefer undergoing $L C A(O R=3.82 ; P=0.02)$. although PCA was associated with shorter hospital stay $(W M D=1.17$ days; $P<0.0001)$ and higher incidence rate of perirenal hematoma $(O R=0.18 ; P<0.0001)$. All the other analyzed parameters were similar, regardless of the surgical approach.

CONCLUSIONS: Patients undergoing PCA have shorter hospital stay and PCA was more frequently used in older patients and posterior tumors. Whereas LCA was associated with lower incidence rate of perirenal hematoma. Further multicenter, prospective and long-term follow-up RCTs are required to verify these findings.

\section{INTRODUCTION}

Over the past decades, the morbidity of small renal masses(SRMs) has increasingly risen, with computed tomography (CT ) imaging is widely applied to various medical disciplines $[1,2]$. The gold standard for the treatment of SRMs is open or laparoscopic partial nephrectomy $(\mathrm{PN})$, and which shows excellent results, with 5-year survival rates approaching 97\% [3, 4] However, PN is associated with intra- and post-operative complication rate of about $20 \%$ [3]. In the course of the past two decades, ablative techniques for instance, cryoablation have emerged as a less invasion treatment option in patients with significant comorbidities that may preclude extirpative surgery $[4,5]$. Initially, cryoablation was applied to treat the patients declining surgical intervention or poor surgical elderly, thus became an alternative choice for SRMs and associated with better oncological outcomes compared with PN [4].

Cryoablation approaches are often performed laparoscopically under direct visualization or percutaneously under image-guided for SRMs. The advantages of laparoscopic cryoablation(LCA) is operation of probes with lower complication under 
Table 1: Characteristics of included studies

\begin{tabular}{|l|c|c|c|c|c|c|}
\hline $\begin{array}{c}\text { First author } \\
\text { year }\end{array}$ & Country & Study interval & Design & LOE & $\begin{array}{c}\text { No.of patients } \\
\text { LCA/PCA }\end{array}$ & $\begin{array}{c}\text { Matching/ } \\
\text { comparable* }\end{array}$ \\
\hline Bandi, 2008 & USA & $2000-2006$ & Retrospective & $3 \mathrm{~b}$ & $58 / 20$ & $1,2,3,5,6,7,10,12$ \\
\hline Derweesh, 2008 & USA & $1997-2007$ & Retrospective & $3 \mathrm{~b}$ & $34 / 26$ & $1,3,4,5,6,7,8,10$, \\
\hline Finley, 2008 & USA & $2003-2007$ & Retrospective & $3 \mathrm{~b}$ & $19 / 18$ & $2,5,7,12$ \\
\hline Goyal, 2012 & USA & $1997-2008$ & Retrospective & $3 \mathrm{~b}$ & $53 / 141$ & $1,3,4,5,7,8,9,10,12$ \\
\hline Hinshaw, 2008 & USA & $2001-2007$ & Retrospective & $3 \mathrm{~b}$ & $60 / 30$ & $1,3,4,7,12$ \\
\hline Kim, 2014 & USA & $2001-2011$ & Retrospective & $3 \mathrm{~b}$ & $145 / 118$ & $1,2,3,4,7,8,12$ \\
\hline Malcolm, 2009 & USA & $2003-2007$ & Retrospective & $3 \mathrm{~b}$ & $46 / 20$ & $1,2,5,7,12$ \\
\hline Mues, 2010 & USA & $2005-2008$ & Retrospective & $3 \mathrm{~b}$ & $81 / 90$ & $1,4,5,7,12$ \\
\hline Rofriguez, 2015 & Spain & $2007-2013$ & Retrospective & $3 \mathrm{~b}$ & $40 / 40$ & $1,2,3,4,6,7,8,9,12$ \\
\hline Strom, 2011 & USA & $1998-2010$ & Retrospective & $3 \mathrm{~b}$ & $84 / 61$ & $1,2,3,6,7,8,12$ \\
\hline Trudeau, 2016 & Canada & $2000-2009$ & Retrospective & $3 \mathrm{~b}$ & $289 / 227$ & $1,3,4,7,9,12$ \\
\hline Tsivian, 2010 & USA & $2001-2008$ & Retrospective & $3 \mathrm{~b}$ & $72 / 123$ & $1,2,3,5,7,8,9,12$ \\
\hline Zargar, 2015 & USA & $1997-2012$ & Retrospective & $3 \mathrm{~b}$ & $275 / 137$ & $1,2,3,4,6,7,12$ \\
\hline
\end{tabular}

$\mathrm{LCA}=$ Laparoscopic cryoablation; $\mathrm{PCA}=$ Percutaneous cryoablation; $\mathrm{LOE}=$ level of evidence.

*:Matching/comparable variable: $1=$ age, $2=\mathrm{BMI}, 3=$ gender, 4=laterality(right/left), 5=number of mass, 6=ASA score, $7=$ tumor size, $8=$ tumor location, 9=CCI(Charlson Comorbidity Index), 10=No of probes used per lesion, 11=cost, 12=follow up

direct visualization. Whereas, the advantages of the percutaneous cryoablation(PCA) are local anesthesia, less cost, shorter hospital stay, shorter recovery time and lower complication rates. In the last few years, several studies of comparing LCA with PCA applied to SRMs have reported perioperative outcomes [6-9]. which included cost, recovery time, hospital stay, procedure time, oncologic and functional outcomes. However, the published outcomes of LCA comparing with PCA have not been evaluated, and no definitive conclusions for reference to guiding their clinical application. Hence, we performed a systematic review of literature with a metaanalysis of the available published literature to compare LCA with PCA with respect to clinical characteristics, perioperative complications and oncological outcomes of SRMs patients.

\section{RESULTS}

\section{Characteristics of eligible studies}

According to search strategy, 13 studies [6-18] were included assessing LCA $v s$. PCA conformed to the inclusion criteria and were applied to performed this meta-analysis (Figure 1). The demographic and clinical characteristics of these literatures were shown in Table 1.

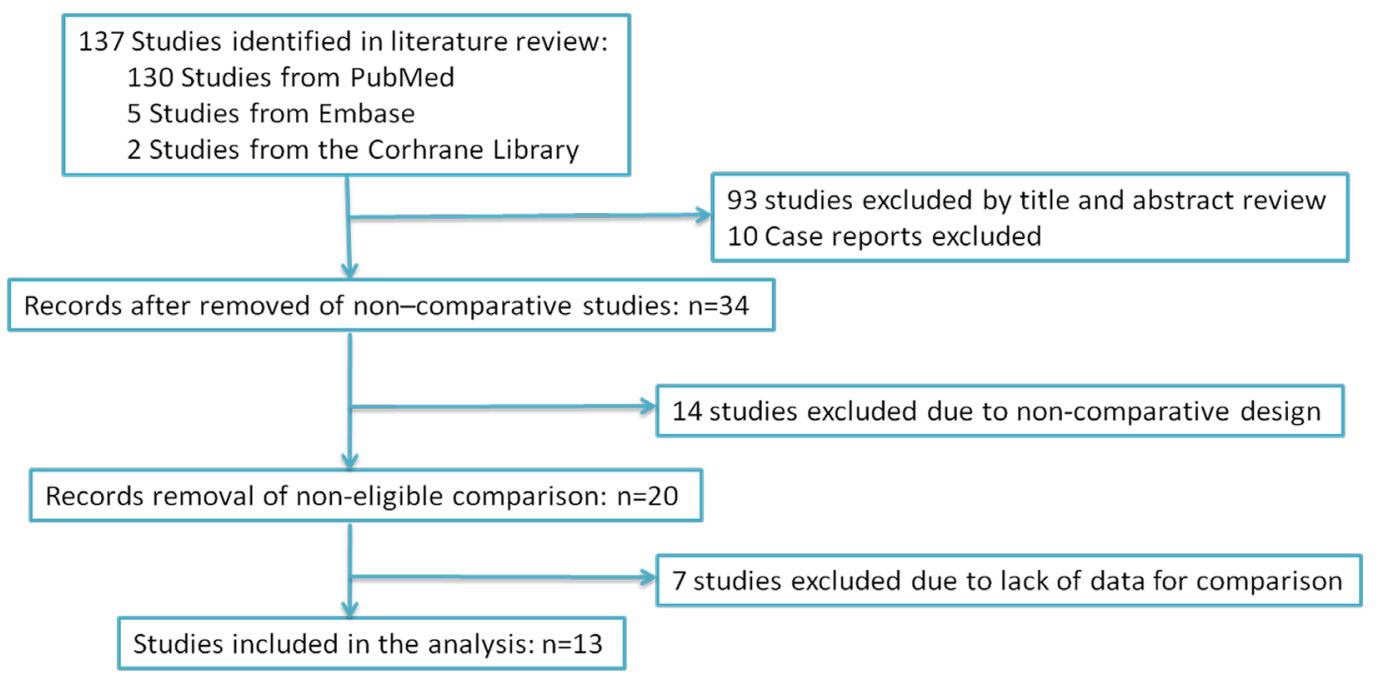

Figure 1: PRISMA diagram. The search strategy and number of studies identified for inclusion in this meta-analysis. 
Table 2: Overall analysis of demographic and clinical characteristics compared LCA with PCA

\begin{tabular}{|c|c|c|c|c|c|c|c|c|}
\hline \multirow{2}{*}{ Outcomes of interest } & \multirow{2}{*}{$\begin{array}{l}\text { No. of } \\
\text { studies }\end{array}$} & \multirow{2}{*}{$\begin{array}{l}\text { No. of patients } \\
\text { LCA/PCA }\end{array}$} & \multirow{2}{*}{$\begin{array}{l}\text { OR/WMD }(95 \% \\
\text { CI })^{\dagger}\end{array}$} & \multirow{2}{*}{$p$-value } & \multicolumn{4}{|c|}{ Study heterogeneity } \\
\hline & & & & & Chi2 & $\mathrm{df}$ & $I^{2}$ & $p$-value \\
\hline Age(year) & 6 & $638 / 412$ & $-0.16[-0.29,-0.04] \dagger$ & 0.01 & 5.43 & 5 & $8 \%$ & 0.37 \\
\hline $\mathrm{BMI}(\mathrm{kg} / \mathrm{m} 2)$ & 5 & $578 / 382$ & $-0.78[-2.43,0.86] \dagger$ & 0.35 & 11.65 & 4 & $66 \%$ & 0.02 \\
\hline Proportion/male & 10 & $1110 / 923$ & $0.89[0.74,1.07]$ & 0.22 & 15.02 & 9 & $40 \%$ & 0.09 \\
\hline Tumor size $(\mathrm{cm})$ & 6 & $444 / / 365$ & $-0.07[-0.28,0.15] \dagger$ & 0.55 & 14.66 & 5 & $66 \%$ & 0.01 \\
\hline $\begin{array}{l}\text { Tumor location } \\
\text { anterior } \\
\text { posterior } \\
\text { central } \\
\text { lateral } \\
\end{array}$ & $\begin{array}{l}6 \\
6 \\
4 \\
2 \\
\end{array}$ & $\begin{array}{l}436 / 538 \\
458 / 543 \\
251 / 380 \\
221 / 276 \\
\end{array}$ & $\begin{array}{c}3.82[1.21,12.07] \\
0.23[0.10,0.54] \\
4.02[0.69,23.48] \\
0.98[0.58,1.65]\end{array}$ & $\begin{array}{c}\mathbf{0 . 0 2} \\
\mathbf{0 . 0 0 0 7} \\
0.12 \\
0.93 \\
\end{array}$ & $\begin{array}{c}60.02 \\
33.05 \\
19.64 \\
0.68 \\
\end{array}$ & $\begin{array}{l}5 \\
5 \\
3 \\
1 \\
\end{array}$ & $\begin{array}{c}92 \% \\
85 \% \\
85 \% \\
0 \% \\
\end{array}$ & $\begin{array}{c}<0.001 \\
<\mathbf{0 . 0 0 1} \\
\mathbf{0 . 0 0 0 2} \\
0.41 \\
\end{array}$ \\
\hline $\begin{array}{l}\text { Tumor polarity } \\
\text { Upper pole } \\
\text { Midpolar } \\
\text { Lower pole }\end{array}$ & $\begin{array}{l}6 \\
6 \\
6\end{array}$ & $\begin{array}{l}458 / 543 \\
458 / 543 \\
458 / 543 \\
\end{array}$ & $\begin{array}{l}1.26[0.94,1.67] \\
1.07[0.64,1.77] \\
0.77[0.44,1.37]\end{array}$ & $\begin{array}{l}0.12 \\
0.80 \\
0.38\end{array}$ & $\begin{array}{l}6.14 \\
15.57 \\
19.59\end{array}$ & $\begin{array}{l}5 \\
5 \\
5\end{array}$ & $\begin{array}{l}19 \% \\
68 \% \\
74 \%\end{array}$ & $\begin{array}{c}0.29 \\
\mathbf{0 . 0 0 8} \\
\mathbf{0 . 0 0 1}\end{array}$ \\
\hline $\begin{array}{l}\text { Preoperative } \\
\text { creatinine }(\mathrm{mg} / \mathrm{dl})\end{array}$ & 2 & $115 / 116$ & $-0.00[-0.13,0.12] \dagger$ & 0.96 & 0.00 & 1 & $0 \%$ & 0.94 \\
\hline
\end{tabular}

$\mathrm{LCA}=$ Laparoscopic cryoablation; $\mathrm{PCA}=$ Percutaneous cryoablation; $\mathrm{OR}=$ odds ratio; $\mathrm{WMD}=$ weighted mean difference; $\mathrm{CI}$ $=$ confidence interval; $\mathrm{BMI}=$ body mass index; $\uparrow: \mathrm{WMD}$

Table 3: Overall analysis of perioperative outcomes comparing LCA with PCA

\begin{tabular}{|c|c|c|c|c|c|c|c|c|}
\hline \multirow{2}{*}{ Outcome of interest } & \multirow{2}{*}{$\begin{array}{l}\text { No. of } \\
\text { studies }\end{array}$} & \multirow{2}{*}{$\begin{array}{l}\text { No.of } \\
\text { patients } \\
\text { LCA/PCA }\end{array}$} & \multirow{2}{*}{ OR/WMD $(95 \% \mathrm{CI})^{\dagger}$} & \multirow{2}{*}{$p$-value } & \multicolumn{4}{|c|}{ Study heterogeneity } \\
\hline & & & & & Chi2 & df & $I^{2}$ & $p$-value \\
\hline Operative time, $\min$ & 3 & $219 / 184$ & $23.10[-37.09,83.29] \dagger$ & 0.45 & 58.41 & 2 & $97 \%$ & $<0.0001$ \\
\hline No of probes used per lesion & 2 & $87 / 167$ & $-0.51[-1.49,0.47]$ & 0.31 & 19.58 & 1 & $95 \%$ & $<0.0001$ \\
\hline Hospital stay,days & 5 & $332 / 355$ & $1.17[0.74,1.61] \dagger$ & $<0.0001$ & 10.51 & 4 & $62 \%$ & 0.03 \\
\hline Transfusion rate & 5 & $265 / 215$ & $2.10[0.79,5.59]$ & 0.14 & 1.85 & 4 & $0 \%$ & 0.76 \\
\hline $\begin{array}{l}\text { Postoperative creatinine }(\mathrm{mg} / \\
\mathrm{dl})\end{array}$ & 2 & $115 / 116$ & $0.11[-0.03,0.26] \dagger$ & 0.12 & 1.64 & 1 & $39 \%$ & 0.20 \\
\hline
\end{tabular}

$\mathrm{LCA}=$ laparoscopic cryoablation; $\mathrm{PCA}=$ percutaneous cryoablation; $\mathrm{OR}=$ odds ratio; $\mathrm{WMD}=$ weighted mean difference; $\mathrm{CI}$ $=$ confidence interval; $\uparrow: \mathrm{WMD}$

\section{Quality of the studies and level of evidence(Table 1)}

In this meta-analysis, the Newcastle-Ottawa Scale quality assessment method of the observational studies [19], and the US Preventive Services Task Force grading system [20] were applied to evaluate the quality of include studies. Also, the demographic variables of LCA and PCA were extracted independently from included literatures (Table 1).

\section{Description of included studies and patients Demographics(Table 2)}

Patients undergoing LCA were significantly younger(WMD $=-0.16$ years; $95 \% \mathrm{CI}:-0.29$ to $-0.04 ; P$ $=0.01)($ Table 2$)$ than PCA, patients with posterior tumors were significantly prefer undergoing PCA than LCA(OR $=0.23 ; 95 \%$ CI: 0.10 to $0.54 ; P=0.0007$ ) (Table 2 ). Whereas patients with anterior tumors were significantly prefer undergoing $\mathrm{LCA}(\mathrm{OR}=3.82 ; 95 \% \mathrm{CI}$ : 1.21 to 12.07 ;
$P=0.02)$ (Table 2) than PCA. There were no statistical differences in term of gender $(\mathrm{OR}=0.89 ; 95 \% \mathrm{CI}: 0.74$ to $1.07 ; P=0.22)$, body mass index(BMI) $(\mathrm{WMD}=-0.78 \mathrm{~kg} /$ $\mathrm{m}^{2} ; 95 \% \mathrm{CI}:-2.43$ to $0.86 ; P=0.35$ ), tumor size (WMD $=-0.07 \mathrm{~cm} ; 95 \% \mathrm{CI}:-0.28$ to $0.15 ; P=0.55)$, tumor polarity(upper pole: $\mathrm{OR}=1.26 ; 95 \% \mathrm{CI}: 0.94$ to $1.67 ; P$ $=0.12$; midpolar: $\mathrm{OR}=1.07 ; 95 \% \mathrm{CI}: 0.64$ to $1.77 ; P=$ 0.180 ; lower pole: $\mathrm{OR}=0.77 ; 95 \% \mathrm{CI}: 0.44$ to $1.37 ; P=$ $0.38)$, and preoperative creatinine $(\mathrm{WMD}=-0.00 \mathrm{mg} / \mathrm{dl}$; 95\% CI: -0.13 to $0.12 ; P=0.96$ ) (Table 2).

\section{Outcomes of perioperative variables(Table 3)}

With respect to perioperative variables, Pooling data of 5 studies $[8,9,13-15]$ involving 687 participants found that PCA was associated with shorter hospital stay than PCA(WMD: 1.17 days; 95\% CI: 0.74 to $1.61 ; P<0.0001$ ) (Figure 2). However, there were no statistically difference between PCA and LCA in term of operative time(WMD = 23.10 minutes; 95\% CI:-37.09 to 83.29; $P=0.45$ ) (Figure $2)$, No of probes used per lesion(OR $=-0.51$; $95 \% \mathrm{CI}$ :1.49 to $0.47 ; P=0.31$ )(Table 3 , Supplementary Figure 
$\mathrm{S} 1)$, transfusion $\operatorname{rate}(\mathrm{OR}=2.10 ; 95 \% \mathrm{CI}: 0.79$ to $5.59 ; P$ $=0.14)($ Table 3 , Supplementary Figure S1), postoperative creatinine $(\mathrm{WMD}=0.11 \mathrm{mg} / \mathrm{dl} ; 95 \% \mathrm{CI}:-0.03$ to $0.26 ; P=$ 0.12)(Table 3, Supplementary Figure S1).

\section{Outcomes of complications(Table 4)}

Pooling data of 11studies [6, 7, 9, 10, 12-18] reported on perioperative complications. There was no statistical difference between LCA and PCA in term of overall complications(OR:1.04; $95 \%$ CI: 0.80 to 1.34 ; $P=0.79)$ (Figure 2). A meticulous classification of all perioperative complications showed that PCA had a higher incidence of perirenal hematoma (OR: 0.18; 95\% CI: 0.08 to $0.43 ; P<0.0001)$ than LCA(Figure 3$)$, whereas there were no statistically significant between LCA and PCA in term of pneumothorax(OR: 0.29 ; 95\% CI: 0.06 to 1.45 ; $P=0.13$ ) (Figure 3), bleeding(OR:1.26; 95\% CI: 0.32 to 4.93; $P=0.74$ ) (Figure 3 ), bowel injury (OR:0.91; 95\% CI: 0.17 to $4.86 ; P=0.91$ ) (Figure 3 ), ileus(OR:1.38; 95\% CI: 0.31 to $6.05 ; P=0.67$ ) (Figure 3 ), urine leak(OR: $0.63 ; 95 \%$ CI: 0.17 to $2.29 ; P=0.48$ )(Figure 3 ), artial fibrillation(OR: 2.45 ; $95 \% \mathrm{CI}: 0.38$ to $15.66 ; P$ $=0.34)($ Table 4 , Supplementary Figure S2), deep venous thrombosis(DVT) (OR:1.45;95\% CI: 0.18 to $11.40 ; P=$ 0.73)(Table 4, Supplementary Figure S2), myocardial infarction(OR:1.59; 95\% CI: 0.37 to $6.77 ; P=0.53$ ) (Table 4, Supplementary Figure S2), and neuropraxia(OR:0.28;

Operative time

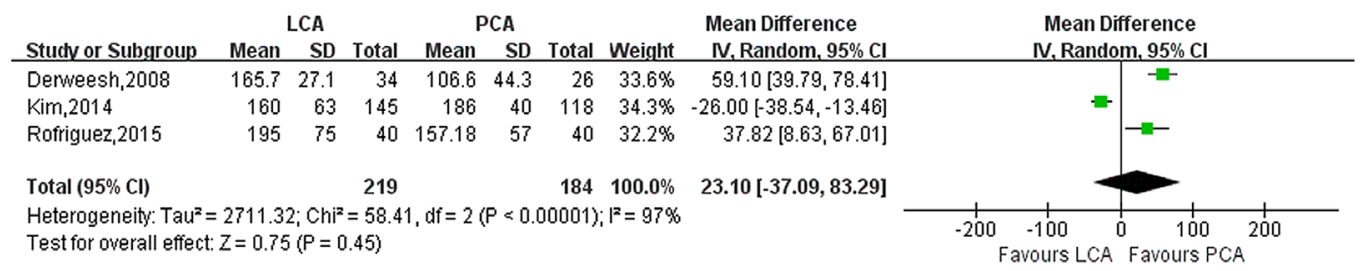

Hospital stay

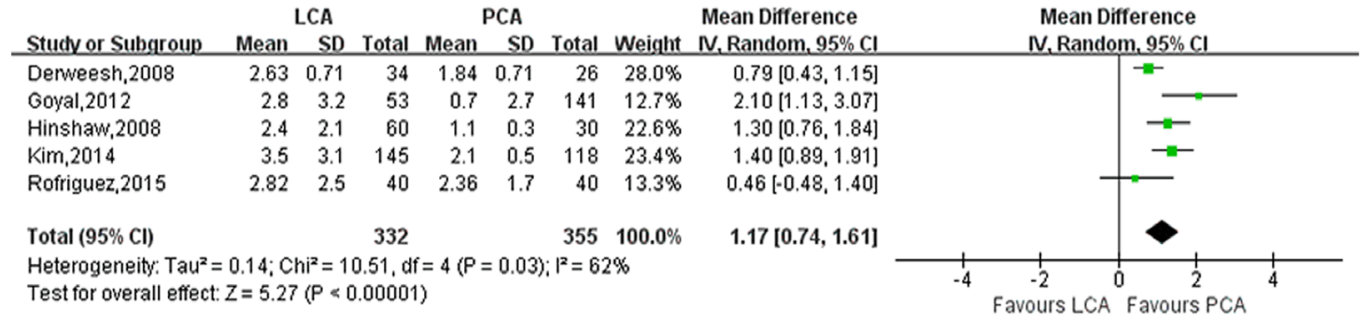

Overall complications

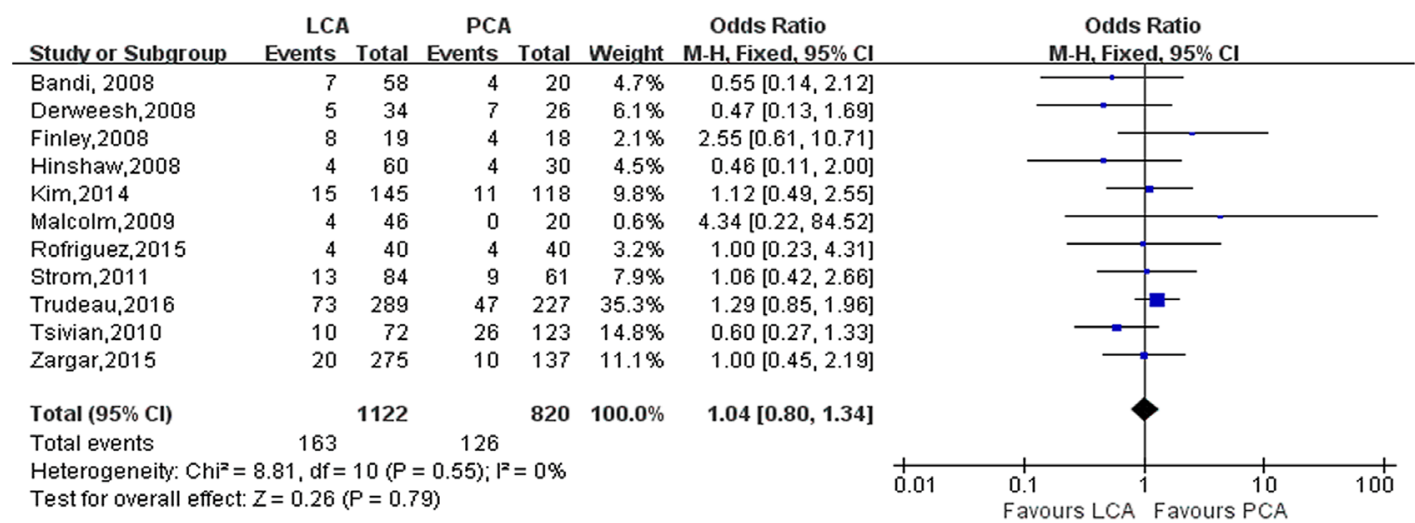

Recurrence rate

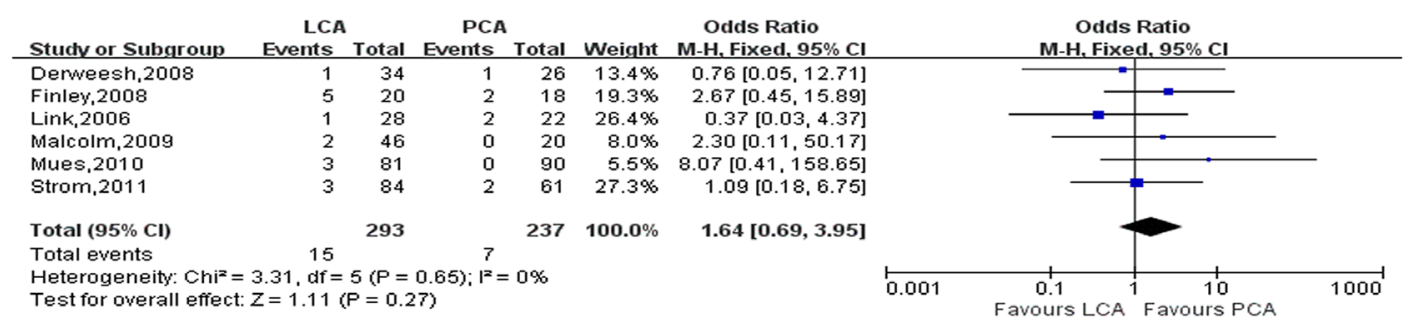

Figure 2: Forest plot and meta-analysis of postoperative outcomes comparing LCA with PCA. LCA = laparoscopic cryoablation; $\mathrm{PCA}=$ percutaneous cryoablation. 


\begin{tabular}{|c|c|c|c|c|c|c|c|}
\hline \multirow[t]{11}{*}{ Hematoma } & Studv or Subgroup & LCA & Total & PCA & & \multicolumn{2}{|r|}{ Odds Ratio } \\
\hline & Bandi, 2008 & 1 & 58 & 1 & 20 & $4.7 \%$ & $0.33[0.02,5.59]$ \\
\hline & Derweesh,2008 & 1 & 34 & 4 & 26 & $14.1 \%$ & $0.17[0.02,1.59]$ \\
\hline & Hinshaw, 2008 & 0 & 60 & 1 & 30 & $6.3 \%$ & $0.16[0.01,4.11]$ \\
\hline & $\mathrm{Kim}, 2014$ & 1 & 145 & 8 & 118 & $28.0 \%$ & $0.10[0.01,0.77]$ \\
\hline & Rofriguez,2015 & 0 & 40 & 5 & 40 & $17.4 \%$ & $0.08[0.00,1.49]$ \\
\hline & Strom,2011 & 3 & 84 & 4 & 61 & $14.3 \%$ & $0.53[0.11,2.45]$ \\
\hline & Tsivian,2010 & 0 & 72 & 6 & 123 & $15.3 \%$ & $0.12[0.01,2.25]$ \\
\hline & Total $(95 \% \mathrm{Cl})$ & & 493 & & 418 & $100.0 \%$ & $0.18[0.08,0.43]$ \\
\hline & Total events & 6 & & 29 & & & \\
\hline & Heterogeneity: $\mathrm{Chi}^{2}=$ & 2.75, $\mathrm{df}=$ & $\begin{aligned} 6(P=0 \\
P\end{aligned}$ & $0.84) ; 1=$ & & & \\
\hline & & & & & & & \\
\hline & & LCA & & PCA & & & Odds Ratio \\
\hline pneumothorax & Studv or Subgroup & Events & Cotal & Events & Total & Weight & M-H, Fixed, $95 \% \mathrm{Cl}$ \\
\hline & Derweesh,2008 & 0 & 34 & 1 & 26 & $25.1 \%$ & $0.25[0.01,6.30]$ \\
\hline & Mues,2010 & 0 & 81 & 1 & 90 & $21.3 \%$ & $0.37[0.01,9.11]$ \\
\hline & Strom,2011 & 0 & 84 & 1 & 61 & $25.9 \%$ & $0.24[0.01,5.96]$ \\
\hline & Tsivian,2010 & 0 & 72 & 2 & 123 & $27.7 \%$ & $0.34[0.02,7.08]$ \\
\hline & Total $(95 \% \mathrm{Cl})$ & & 271 & & 300 & $100.0 \%$ & $0.29[0.06,1.45]$ \\
\hline & Total events & 0 & & 5 & & & \\
\hline & Heterogeneity: $\mathrm{Chi}^{2}=$ & $0.05, \mathrm{df}=$ & $3(P=1$ & $1.00) ; 1^{2}=$ & & & \\
\hline & Test for overall effect: & 1.50( & $P=0.13$ & & & & \\
\hline
\end{tabular}

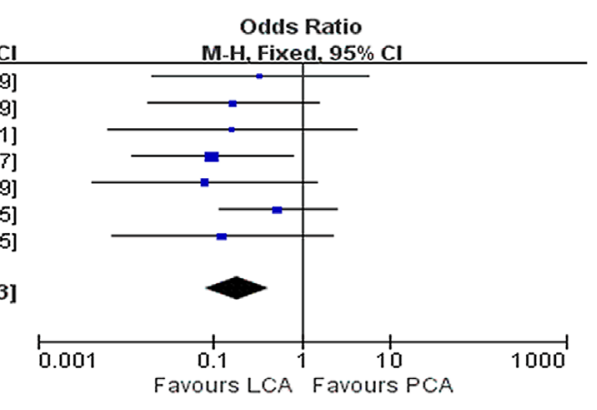

Test

\begin{tabular}{|c|c|c|c|c|c|c|c|}
\hline \multirow[t]{6}{*}{ Bleeding } & \multicolumn{3}{|c|}{ LCA } & \multicolumn{2}{|c|}{ PCA } & Weight & $\begin{array}{l}\text { Odds Ratio } \\
\text { M-H, Fixed, 95\% Cl }\end{array}$ \\
\hline & Bandi, 2008 & 1 & 58 & 0 & 20 & $19.4 \%$ & $1.07[0.04,27.31]$ \\
\hline & Finley, 2008 & 4 & 12 & 2 & 9 & $41.2 \%$ & $1.75[0.24,12.64]$ \\
\hline & Tsivian,2010 & 1 & 72 & 2 & 123 & $39.4 \%$ & $0.85[0.08,9.57]$ \\
\hline & Total $(95 \% \mathrm{Cl})$ & & 142 & & 152 & $100.0 \%$ & $1.26[0.32,4.93]$ \\
\hline & $\begin{array}{l}\text { Total events } \\
\text { Heterogeneity: Chi } \\
\text { Test for overall effer }\end{array}$ & $\begin{array}{r}6 \\
0.22, d f= \\
Z=0.34\end{array}$ & $\begin{array}{l}2 \stackrel{P}{P}= \\
P=0.7\end{array}$ & 4) & & & \\
\hline
\end{tabular}

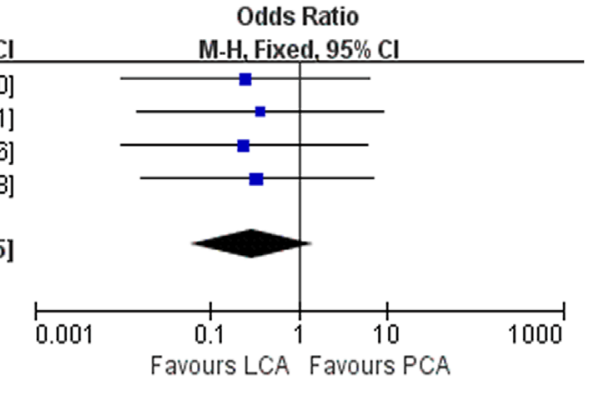

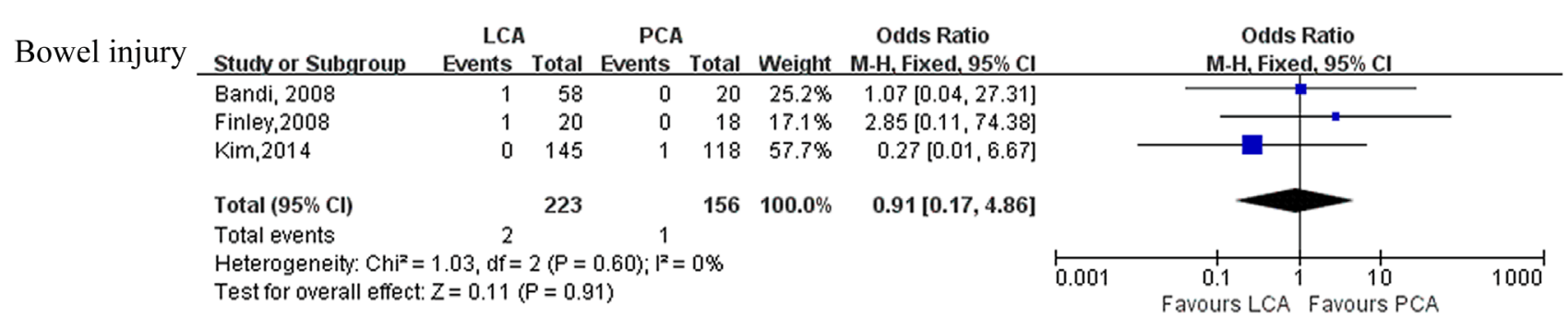

$\begin{array}{lcccc} & \text { LCA } & \text { PCA } & \text { Odds Ratio } \\ \text { Ileus Study or Subgroup } & \text { Events Total Events Total Weight } & \text { M-H. Fixed. 95\% CI }\end{array}$ \begin{tabular}{lrrrrrr} 
Study or Subgroup & Events & Total & Events & Total & Weight & M-H. Fixed, 95\% Cl \\
\hline Malcolm, 2009 & 2 & 46 & 0 & 20 & $21.4 \%$ & $2.30[0.11,50.17]$ \\
Strom,2011 & 2 & 84 & 0 & 61 & $18.4 \%$ & $3.73[0.18,79.04]$
\end{tabular} $\begin{array}{llllrrr}\text { Strom,2011 } & 2 & 84 & 0 & 61 & 18.4 \% & 3.73[0.18,79.04] \\ \text { Tsivian,2010 } & 0 & 72 & 2 & 123 & 60.2 \% & 0.34[0.02,7.08]\end{array}$

$\begin{array}{lllllll}\text { Total }(95 \% \mathrm{Cl}) & 202 & & 204 & 100.0 \% & 1.38[0.31,6.05] \\ \text { Total events } & 4 & & 2 & & & \end{array}$

Heterogeneity: $\mathrm{Chi}^{2}=1.34, \mathrm{df}=2(\mathrm{P}=0.51) ; \mathrm{I}^{2}=0 \%$

Test for overall effect: $Z=0.43(P=0.67)$

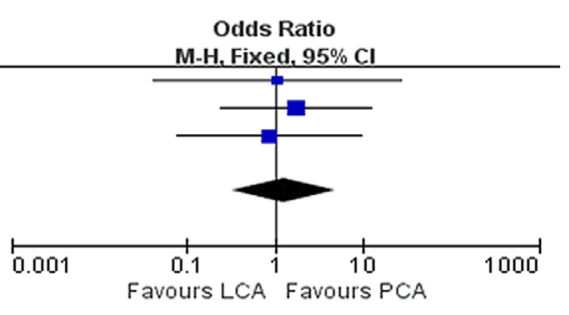


Table 4: Overall analysis of complications comparing LCA and PCA

\begin{tabular}{|l|c|c|c|c|c|c|c|c|}
\hline \multirow{2}{*}{ Outcome of interest } & \multirow{2}{*}{$\begin{array}{c}\text { No. of } \\
\text { studies }\end{array}$} & $\begin{array}{c}\text { No.of patients } \\
\text { LCA/PCA }\end{array}$ & \multirow{2}{*}{ OR (95\%CI) } & \multirow{2}{*}{ p-value } & \multicolumn{4}{|c|}{ Study heterogeneity } \\
\cline { 7 - 9 } & & & & \multicolumn{2}{|c|}{ Chi2 } & df & $\boldsymbol{I}^{\mathbf{2}}$ & $\boldsymbol{p}$-value \\
\hline Overall complications & 11 & $1122 / 820$ & $1.04[0.80,1.34]$ & 0.79 & 8.81 & 10 & $0 \%$ & 0.55 \\
\hline Artial fibrillation & 3 & $275 / 261$ & $2.45[0.38,15.66]$ & 0.34 & 0.46 & 2 & $0 \%$ & 0.79 \\
\hline Bleeding & 3 & $142 / 152$ & $1.26[0.32,4.93]$ & 0.74 & 0.22 & 2 & $0 \%$ & 0.90 \\
\hline Bowel injury & 3 & $223 / 156$ & $0.91[0.17,4.86]$ & 0.91 & 1.03 & 2 & $0 \%$ & 0.60 \\
\hline DVT & 2 & $165 / 136$ & $1.45[0.18,11.40]$ & 0.73 & 0.21 & 1 & $0 \%$ & 0.64 \\
\hline Hematoma & 7 & $493 / 418$ & $0.18[0.08,0.43]$ & $<\mathbf{0 . 0 0 0 1}$ & 2.75 & 6 & $0 \%$ & 0.84 \\
\hline Ileus & 3 & $202 / 204$ & $1.38[0.31,6.05]$ & 0.67 & 1.34 & 2 & $0 \%$ & 0.51 \\
\hline Myocardial infarction & 4 & $573 / 468$ & $1.59[0.37,6.77]$ & 0.53 & 1.39 & 3 & $0 \%$ & 0.71 \\
\hline Neuropraxia & 2 & $118 / 50$ & $0.28[0.05,1.65]$ & 0.16 & 1.96 & 1 & $49 \%$ & 0.16 \\
\hline Pneumothorax & 4 & $271 / 300$ & $0.29[0.06,1.45]$ & 0.13 & 0.05 & 3 & $0 \%$ & 1.00 \\
\hline Urine leak & 3 & $190 / 173$ & $0.63[0.17,2.29]$ & 0.48 & 5.44 & 2 & $63 \%$ & 0.07 \\
\hline
\end{tabular}

$\mathrm{LCA}=$ laparoscopic cryoablation; $\mathrm{PCA}=$ percutaneous cryoablation; $\mathrm{OR}=$ odds ratio; $\mathrm{WMD}=$ weighted mean difference; $\mathrm{CI}$ $=$ confidence interval; DVT $=$ deep venous thrombosis.

95\% CI: 0.05 to $1.65 ; P=0.16$ ) (Table 4 , Supplementary Figure S2).

\section{Outcomes of pathological and oncological variables(Table 5)}

Pooling data of five $[8,9,11,13,18]$ and seven $[6$, $8,9,11,12,14,18]$ studies reported pathologic outcomes and local recurrence, respectively. The forest plot indicated that there was no statistical difference in term of postoperative pathologic outcomes (malignancy: OR: $1.21 ; 95 \%$ CI: 0.24 to $6.22 ; P=0.82$; benign: OR: 0.77 ; 95\% CI: 0.16 to $3.74 ; P=0.74$ )(Table 5 , Supplementary Figure S3) and recurrence rate(OR: $0.95 ; 95 \%$ CI: 0.65 to $1.40 ; P=0.81$ ) (Figure 4). And there were also no statistical differences between PCA and LCA in term of 3 -year disease-free survival(DFS)(OR: 0.57; 95\% CI: 0.25 to $1.33 ; P=0.19)$, 3 -year overall survival(OS) (OR: 0.87 ; 95\% CI: 0.48 to $1.55 ; P=0.63), 5$-year OS(OR: 0.82 ; 95\% CI: 0.57 to $1.18 ; P=0.29), 5$-year recurrence-free survival(RFS)(OR: $0.83 ; 95 \%$ CI: 0.56 to $1.22 ; P=0.34$ ) (Figure 4, Table 5).

\section{DISCUSSION}

Laparoscopic PN approaches was associated with better surgical outcomes and had been recommend as the "golden standard" for SRMs. A large number of patients diagnosed with SRMs are aged people with comorbidities, hence, there is a high risk with these invasion surgical operations for these patients. Moreover, many of these patients carry competing risks which pose a greater mortality risk than do the SRM [21, 22]. Nowadays, cryoablation (CA) has attracted more interest for it in situ treatment tumor and less invasive. The cryoablation approaches offer several advantages than surgical excision, such as lower perioperative complications, shorter hospital stay, absence of renal ischemia, quicker time to recovery $[22,23]$. As clinical outcome data of SRMs cryoablation with percutaneous and laparoscopic approaches begin to accumulate, The question arises as to which is preferable. Therefore, we conducted a meta-analysis to compared LCA with PCA and to evaluate its safety and feasibility.

Many surgeons general choose younger and good comorbidity condition patients to preform LCA. And our results showed that patients with older age and posterior tumor are more likely to undergo PCA. The reason of this differences was that the older and posterior tumor patients choose PCA to avoid injury of adjacent organs and decreased the intra- and post-operative complications. We also compared preoperative and postoperative creatinine level changes between the two approaches, and the results showed no significant difference.

Our study indicated that PCA provided a shorter hospital stay than LCA (WMD:1.17 days; $P<0.0001$ ). The reason were that PCA to be performed on an outpatient basis, and avoidance of a general anesthetic can lead to significant saving in cost and time for patients and hospitals [24]. But our study results showed that there were no statistical differences between LCA and PCA in term of the other postoperative variables, such as operative time, No of probes used per lesion, and transfusion rate.

Hui et al [25] performed meta-analysis found that patients underwent surgically cryoablation had higher major complications than PCA, but our results showed that there was no statistical significant between LCA and PCA with respect to overall complications(OR:1.04; $P=0.79$ ). And Kim et al [9] showed similar results and strengthens our results. This difference may be attributed to literature included in Hui's meta-analysis was not comparative studies and the sample was small. A subgroup analysis of overall complications indicated that PCA was associated with higher incidence rate of perirenal hematoma(OR: 
$0.18 ; P<0.0001)$. The renal parenchymal fracture after LCA and PCA result in perirenal hematoma were the most common, and LCA was performed under the direction of visualization while PCA was guided by CT or ultrasound, This difference lead to PCA had higher incidence of perirenal hematoma than LCA. However, there were no significant differences between PCA and LCA in term of artial fibrillation, bleeding, bowel injury, DVT, ileus, neuropraxia, pneumothorax, urine leak. One issue is the grading of complications and parameters of complication were not always reported in a available standardized way in included literature, while another issue is that the sample of the included studies is small. More multicenter, large sample, long follow-up RCTs are needed to offer more details about complications and further verify those findings.

As for the oncologic outcomes, our data showed that there were no statistical differences in term of pathologic outcomes(malignancy: OR: $1.21 ; P=0.82$; benign: OR: $0.77 ; P=0.74$ ) and recurrence rate(OR: $0.95 ; P=0.81$ ) compared with LCA group. There were also no statistical differences in term of 3-year DFS(OR: $0.57 ; P=0.19$ ),

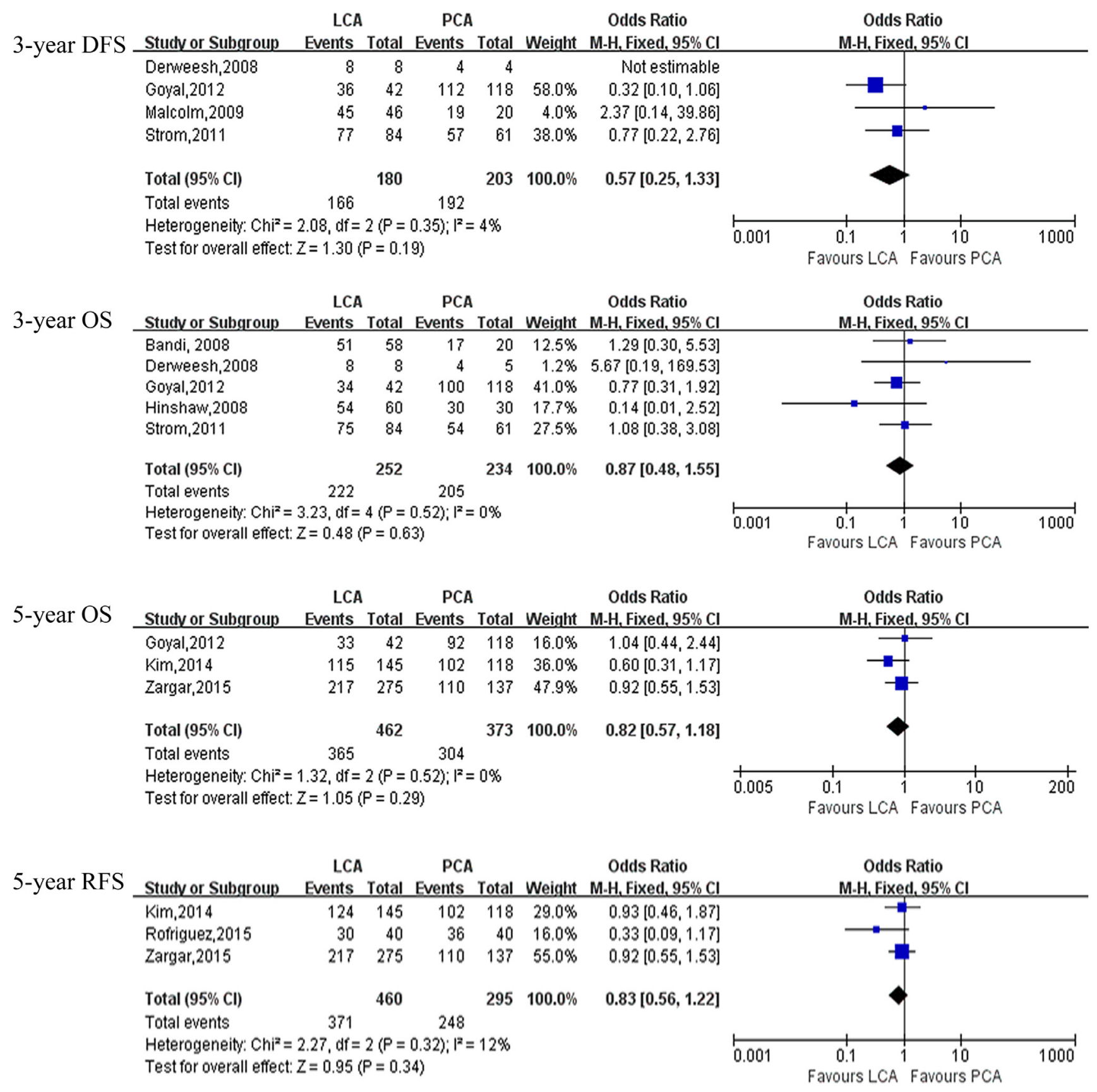

Figure 4: Forest plot and meta-analysis of oncological outcomes comparing LCA with PCA. LCA = laparoscopic cryoablation; $\mathrm{PCA}=$ percutaneous cryoablation. 
Table 5: Overall analysis of pathologic and oncological outcomes comparing LCA with PCA

\begin{tabular}{|l|c|c|c|c|c|c|c|c|}
\hline \multirow{2}{*}{ Outcome of interest } & \multirow{2}{*}{$\begin{array}{c}\text { No.of } \\
\text { studies }\end{array}$} & $\begin{array}{c}\text { No.of } \\
\text { patients } \\
\text { LCA/PCA }\end{array}$ & \multirow{2}{*}{ OR (95\%CI) } & \multirow{2}{*}{$\boldsymbol{p}$-value } & \multicolumn{4}{|c|}{ Study heterogeneity } \\
\cline { 6 - 9 } & & & & & Chi2 $\mathbf{d f}$ & $\boldsymbol{I}^{\mathbf{2}} \boldsymbol{p}$-value \\
\hline Pathologic & & & & & & & \\
\hline Malignancy & 5 & $591 / 367$ & $1.21[0.24,6.22]$ & 0.82 & 86.38 & 4 & $95 \%$ & $<\mathbf{0 . 0 0 0 1}$ \\
\hline Benign & 5 & $591 / 367$ & $0.77[0.16,3.74]$ & 0.74 & 83.84 & 4 & $95 \%$ & $<\mathbf{0 . 0 0 0 1}$ \\
\hline Recurrence rate & 7 & $756 / 597$ & $0.95[0.65,1.40]$ & 0.81 & 7.75 & 6 & $23 \%$ & 0.26 \\
\hline 3-year DFS & 4 & $180 / 203$ & $0.57[0.25,1.33]$ & 0.19 & 2.08 & 2 & $4 \%$ & 0.35 \\
\hline 3-year OS & 5 & $252 / 234$ & $0.87[0.48,1.55]$ & 0.63 & 3.23 & 4 & $0 \%$ & 0.52 \\
\hline 5-year OS & 3 & $462 / 373$ & $0.82[0.57,1.18]$ & 0.29 & 1.32 & 2 & $0 \%$ & 0.52 \\
\hline 5-year RFS & 3 & $460 / 295$ & $0.83[0.56,1.22]$ & 0.34 & 2.27 & 2 & $12 \%$ & 0.32 \\
\hline
\end{tabular}

$\mathrm{LCA}=$ laparoscopic cryoablation; $\mathrm{PCA}=$ percutaneous cryoablation; $\mathrm{DFS}=$ disease-free survival; $\mathrm{OS}=\mathrm{overall}$ survival; $\mathrm{RFS}=$ recurrence-free survival; $\mathrm{OR}=$ odds ratio; $\mathrm{WMD}=$ weighted mean difference; $\mathrm{CI}=$ confidence interval.

3-year OS(OR: $0.87 ; P=0.63), 5$-year OS(OR: $0.82 ; P$ $=0.29$ ), 5-year RFS (OR: $0.83 ; P=0.34$ ) between the two groups. Goyal et al [8] demonstrated the OS, RFS and CSF were $85.12 \%, 95.56 \%$ and $98 \%$ for the PCA group at 3 years and $81.72 \%, 93.75 \%$ and $100 \%$ for the surgical cryoablation at 3 years, respectively. Strom et al [12] reported on 145 patients with 42.3 months of follow-up with a significant difference local recurrence in the PCA and LCA group(16.4\% vs 5.9\%); and the 3-year OS and DFS were $88.9 \%, 93.7 \%$ for the PCA group and $89.3 \%$, $91.7 \%$ for the LCA group, respectively. Zargar et al [18] reported on 412 patients who underwent PCA and LCA; the 5-year OS and RFS were $82 \%, 80 \%$ for PCA group and $89 \%, 79 \%$ for LCA group, respectively. Our data showed that there were no significant differences in OS and RFS between PCA and LCA. But there is exist selection bias in term of oncologic outcomes between the two groups, for example, patients with older and high risk comorbidities are prefer undergoing PCA. Additionally, The follow-up duration have an effect on the oncological outcomes of two approaches.

However, There were several limitations exist when analyzed and interpreting results in our meta-analysis. The major limitation is lack of well designed prospective, randomized control studies in our meta-analysis. Indeed, there was no RCTs in our included literatures. Secondly, there was existed heterogeneities of studies, especially in the comparing of the continuous data such as the length of hospital stay, operative time, and these parameters were influenced by the heterogeneities of patients' conditions, surgeon's surgical skills and the sample size of studies.

Nevertheless, Our meta-analysis compared LCA with PCA for treatment of SRMs was performed with adequate studies available for analysis. We used all available variables from included studies, including demographic and clinical characteristics, operative time, overall complications and oncological outcomes, to compare LCA with PCA for SRMs and to assess the evidence of the included literature with strict criteria. Here, our meta-analysis maybe provide up to date conclusions for the advantages and disadvantages of two approaches for treatment of SMRs.

In conclusion, LCA and PCA have similar shortterm outcomes for SRMs in selected patients. Patients undergoing PCA have shorter hospital stay and PCA was more frequently used in posterior tumors and older patients, whereas LCA was associated with lower incidence of perirenal hematoma.

\section{MATERIALS AND METHODS}

\section{Literature search strategy}

According to the Cochrane Handbook recommendations, a systematic review of published literature was performed [26]. No ethicissues get involved in this dissertation. A systematic dissertation was conducted using Medline, Embase, Pubmed, CNKI and all relevant studies has been identified by the Cochrane Library. The following key words were used: "comparative studies", "laparoscopic cryoablation", "percutaneous cryoablation", "laparoscopic renal cryoablation", "percutaneous renal cryoablation", “cryoablation”, and "small renal masses".

\section{Data extraction and outcomes of interest}

Two of the authors(JKH and TK) extracted data from the selected studies including: author identification, country, publication years, study design, age, No. of patients, operative approaches that were mentioned previously, and results of intervention. All disagreements about eligibility were reached a consensus through authors discussion. Perioperative outcomes including operative time, overall complications, Length of hospital stay(LOS), and oncological outcomes were compared between the two methods from all the studies that were finally selected. 
Overall complications were graded on the basis of the Clavien-Dindo system [27].

\section{Inclusion criteria and exclusion criteria}

Studies should satisfy the following requirements (1) to compare LCA with PCA (2) to display on outcome of two approaches (3) to document the surgery as LCA or PCA (4) to clearly document indications for cryoablation with SRMs. Studies will be excluded if (1) the study was not satisfied inclusion criteria or (2) the outcomes of literature were not mentioned or the parameters were impossible to analysis for either LCA or PCA from the published findings.

\section{Study quality assessment}

In accordance with the criteria of Centre for Evidence-Based Medicine in Oxford, we evaluated the level of evidence(LOE) of included sixteen studies. The Jaded Score was applied to evaluated the methodological quality of RCTs [28]. The Newcastle-Ottawa Scale(NOS) was applied to assessed the methodological quality of non-RCTs observational studies [19]. Two authors(JKH and GXL) evaluated the quality of the studies and discrepancies were rechecked by the third reviewer(CHB) and consensus was achieved by discussion.

\section{Statistical analysis}

All meta-analysis were conducted by Review Manger 5.3(Cochrane Collaboration, Oxford, UK). Continuous and dichotomous variables were calculated by weighted mean differences (WMDs) and odds ratios(ORs). All analysis results were reported with $95 \%$ confidence intervals(CIs). $\mathrm{I}^{2}$ test and chi-square-based $\mathrm{Q}$ test were applied to evaluated the quantity of heterogeneity, and when $\mathrm{I}^{2}>50 \%$, the evidence was considered to have substantial heterogeneity, the random- effects(RE) model would be applied, otherwise, the fixed effects(FE) model was applied. The presence of publication bias was evaluated by Egger's test and funnel plot. Sensitivity analysis were used to estimate the influence of studies with a high risk of bias on the overall effect.

\section{Abbreviations}

$\mathrm{LCA}=$ laparoscopic cryoablation; $\mathrm{PCA}=$ percutaneous cryoablation; $\mathrm{CA}=$ cryoablation; $\mathrm{SRMs}=$ small renal masses; $\mathrm{PN}=$ Partial nephrectomy; $\mathrm{LOE}=$ The level of evidence; WMDs = weighted mean differences; ORs $=$ odds ratios; $\mathrm{CIs}=$ confidence intervals; $\mathrm{RE}=$ random- effects; $F E$ = fixed effects; DFS = disease-free survival; OS = overall survival; RFS= recurrence-free survival.

\section{CONFLICTS OF INTEREST}

All authors declare no conflicts of interest, including specific financial interests or relationships or affiliations relevant to the subject matter in the manuscript.

\section{REFERENCES}

1. Black WC, Welch HG. Advances in diagnostic imaging and overestimations of disease prevalence and the benefits of therapy. N Engl J Med. 1993; 328: 1237-43. doi: 10.1056/ NEJM199304293281706.

2. Hollingsworth JM, Miller DC, Daignault S, Hollenbeck BK. Rising incidence of small renal masses: a need to reassess treatment effect. J Natl Cancer Inst. 2006; 98: 1331-4. doi: 10.1093/jnci/djj362.

3. Emara AM, Kommu SS, Hindley RG, Barber NJ. Robotassisted partial nephrectomy vs laparoscopic cryoablation for the small renal mass: redefining the minimally invasive 'gold standard'. BJU Int. 2014; 113: 92-9. doi: 10.1111/ bju. 12252.

4. Campbell SC, Novick AC, Belldegrun A, Blute ML, Chow GK, Derweesh IH, Faraday MM, Kaouk JH, Leveillee RJ, Matin SF, Russo P, Uzzo RG, Practice Guidelines Committee of the American Urological A. Guideline for management of the clinical T1 renal mass. J Urol. 2009; 182: 1271-9. doi: 10.1016/j.juro.2009.07.004.

5. Ljungberg B, Bensalah $\mathrm{K}$, Canfield S, Dabestani S, Hofmann F, Hora M, Kuczyk MA, Lam T, Marconi L, Merseburger AS, Mulders P, Powles T, Staehler M, et al. EAU guidelines on renal cell carcinoma: 2014 update. Eur Urol. 2015; 67: 913-24. doi: 10.1016/j.eururo.2015.01.005.

6. Bandi G, Hedican S, Moon T, Lee FT, Nakada SY. Comparison of Postoperative Pain, Convalescence, and Patient Satisfaction after Laparoscopic and Percutaneous Ablation of Small Renal Masses. Journal of Endourology. 2008; 22: 963-8. doi: 10.1089/end.2007.0261.

7. Finley DS, Beck S, Box G, Chu W, Deane L, Vajgrt DJ, McDougall EM, Clayman RV. Percutaneous and laparoscopic cryoablation of small renal masses. J Urol. 2008; 180: 492-8; discussion 8. doi: 10.1016/j. juro.2008.04.019.

8. Goyal J, Verma P, Sidana A, Georgiades CS, Rodriguez R. Single-center comparative oncologic outcomes of surgical and percutaneous cryoablation for treatment of renal tumors. J Endourol. 2012; 26: 1413-9. doi: 10.1089/ end.2012.0244.

9. Kim EH, Tanagho YS, Saad NE, Bhayani SB, Figenshau RS. Comparison of laparoscopic and percutaneous cryoablation for treatment of renal masses. Urology. 2014; 83: 1081-7. doi: 10.1016/j.urology.2013.10.081. 
10. Malcolm JB, Berry TT, Williams MB, Logan JE, Given RW, Lance RS, Barone B, Shaves S, Vingan H, Fabrizio MD. Single center experience with percutaneous and laparoscopic cryoablation of small renal masses. J Endourol. 2009; 23: 907-11. doi: 10.1089/end.2008.0608.

11. Mues AC, Okhunov Z, Haramis G, D'Agostino H, Shingleton BW, Landman J. Comparison of percutaneous and laparoscopic renal cryoablation for small $(<3.0 \mathrm{~cm})$ renal masses. J Endourol. 2010; 24: 1097-100. doi: 10.1089/ end.2010.0067.

12. Strom KH, Derweesh I, Stroup SP, Malcolm JB, L'Esperance J, Wake RW, Gold R, Fabrizio M, PalazziChuras K, Gu X, Wong C. Second prize: Recurrence rates after percutaneous and laparoscopic renal cryoablation of small renal masses: does the approach make a difference? J Endourol. 2011; 25: 371-5. doi: 10.1089/end.2010.0239.

13. Derweesh IH, Malcolm JB, Diblasio CJ, Giem A, Rewcastle JC, Wake RW, Patterson AL, Gold R. Single center comparison of laparoscopic cryoablation and CT-guided percutaneous cryoablation for renal tumors. J Endourol. 2008; 22: 2461-7. doi: 10.1089/end.2008.0196.

14. Hinshaw JL, Shadid AM, Nakada SY, Hedican SP, Winter TC, 3rd Lee FT Jr. Comparison of percutaneous and laparoscopic cryoablation for the treatment of solid renal masses. AJR Am J Roentgenol. 2008; 191: 1159-68. doi: 10.2214/AJR.07.3706.

15. Rodriguez Faba O, Sanguedolce F, Grange P, Kooiman G, Bakavicius A, De la Torre P, Palou J. Kidney cancer focal cryoablation trend: does location or approach matter? World J Urol. 2015. doi: 10.1007/s00345-015-1716-z.

16. Trudeau V, Larcher A, Boehm K, Dell'Oglio P, Sun M, Tian Z, Briganti A, Shariat SF, Jeldres C, Karakiewicz PI. Comparison of Postoperative Complications and Mortality Between Laparoscopic and Percutaneous Local Tumor Ablation for T1a Renal Cell Carcinoma: A Populationbased Study. Urology. 2016; 89: 63-8. doi: 10.1016/j. urology.2015.08.043.

17. Tsivian M, Chen VH, Kim CY, Zilberman DE, Mouraviev V, Nelson RC, Albala DM, Polascik TJ. Complications of laparoscopic and percutaneous renal cryoablation in a single tertiary referral center. Eur Urol. 2010; 58: 142-7. doi: 10.1016/j.eururo.2010.03.035.

18. Zargar H, Samarasekera D, Khalifeh A, Remer EM, O’Malley C, Akca O, Autorino R, Kaouk JH. Laparoscopic vs percutaneous cryoablation for the small renal mass: 15year experience at a single center. Urology. 2015; 85: 8505. doi: 10.1016/j.urology.2015.01.004.

19. Stang A. Critical evaluation of the Newcastle-Ottawa scale for the assessment of the quality of nonrandomized studies in meta-analyses. Eur J Epidemiol. 2010; 25: 603-5. doi: 10.1007/s10654-010-9491-z.
20. clark PE. Assessing the Quality of Randomized Trials:Reliability of the Jadad Scale. 1999. doi: 10.1590/ s1677-55382011000200002.

21. Tracy CR, Raman JD, Donnally C, Trimmer CK, Cadeddu JA. Durable oncologic outcomes after radiofrequency ablation: experience from treating 243 small renal masses over 7.5 years. Cancer. 2010; 116: 3135-42. doi: 10.1002/ cncr.25002.

22. Zargar H, Atwell TD, Cadeddu JA, de la Rosette JJ, Janetschek G, Kaouk JH, Matin SF, Polascik TJ, ZargarShoshtari K, Thompson RH. Cryoablation for Small Renal Masses: Selection Criteria, Complications, and Functional and Oncologic Results. Eur Urol. 2016; 69: 116-28. doi: 10.1016/j.eururo.2015.03.027.

23. Klatte $\mathrm{T}$, Kroeger N, Zimmermann U, Burchardt M, Belldegrun AS, Pantuck AJ. The contemporary role of ablative treatment approaches in the management of renal cell carcinoma (RCC): focus on radiofrequency ablation (RFA), high-intensity focused ultrasound (HIFU), and cryoablation. World J Urol. 2014; 32: 597-605. doi: 10.1007/s00345-014-1284-7.

24. Bang HJ, Littrup PJ, Goodrich DJ, Currier BP, Aoun HD, Heilbrun LK, Vaishampayan U, Adam B, Goodman AC. Percutaneous cryoablation of metastatic renal cell carcinoma for local tumor control: feasibility, outcomes, and estimated cost-effectiveness for palliation. J Vasc Interv Radiol. 2012; 23: 770-7. doi: 10.1016/j.jvir.2012.03.002.

25. Hui GC, Tuncali K, Tatli S, Morrison PR, Silverman SG. Comparison of percutaneous and surgical approaches to renal tumor ablation: metaanalysis of effectiveness and complication rates. J Vasc Interv Radiol. 2008; 19: 131120. doi: 10.1016/j.jvir.2008.05.014.

26. Liberati A, Altman DG, Tetzlaff J, Mulrow C, Gotzsche PC, Ioannidis JP, Clarke M, Devereaux PJ, Kleijnen J, Moher D. The PRISMA statement for reporting systematic reviews and meta-analyses of studies that evaluate health care interventions: explanation and elaboration. J Clin Epidemiol. 2009; 62: e1-34. doi: 10.1016/j. jclinepi.2009.06.006.

27. Dindo D, Demartines N, Clavien PA. Classification of Surgical Complications. Annals of Surgery. 2004; 240: 20513. doi: 10.1097/01.sla.0000133083.54934.ae.

28. Clark HD, Wells GA, Huet C, McAlister FA, Salmi LR, Fergusson D, Laupacis A. Assessing the quality of randomized trials: reliability of the Jadad scale. Control Clin Trials. 1999; 20: 448-52. doi: 10.1016/s01972456(99)00026-4. 